\title{
Construction and Reflection on the Innovation Mode of Piano Teaching
}

\author{
Xiaolei Zhang \\ (Born in November,1983)Female, Han, Deputy director of the office, Lecturer, Master,Keyboard \\ playing \\ Qilu Normal University \\ (Shandong,China 250013)
}

\section{Keywords: Piano teaching; Innovation; Mode}

\begin{abstract}
With the development of the times, the education mode is also in constant innovation, and the piano education can train students' theory and skills training, innovation helps to cultivate comprehensive talents. This article from the status of piano teaching, summarizes the purpose and principle of the construction of piano teaching innovation model, mainly constructed four kinds of piano teaching innovation modes, and puts forward the innovation platform by using virtual live in piano teaching. To maximize the role of piano education in enhancing students' creativity.

The innovation of theory and practice in education level is the inevitable requirement of education in the new period, and it is China's education system focusing on the subject, it relates with China's education which can cultivate high-quality talents, and modern university reform relates to the innovation of teaching mode that is the future direction of sustainable development. The study of piano itself requires the participation of students' creative thinking, and the innovation of piano teaching is also an inevitable way for our country to develop music. Piano Teaching in Colleges and universities must adapt to the needs of the development, the innovation mentioned in the schedule firmly grasp the direction of reform with the innovative integration of piano teaching and the cultivation of innovation talents. [1]
\end{abstract}

\section{The Purpose of Constructing Piano Teaching Innovation Model}

Any education has a certain goal, the success of education must rely on a variety of ways to achieve the established goals. Piano Teaching in China's education has been in the field for many years, and for a long time, the piano teaching and learning is paying attention to piano skills, such as music education. And the true meaning of all education is to improve the quality of students and improve the students' creative ability through the improvement of students' aesthetic level. The piano education modes tend to deviate from the track with losing their appeal, the student accepts the rote knowledge of music which are almost inhuman skill training, after a considerable period of time, the traditional piano education will weaken the creative enthusiasm of students. [2] So the construction of innovative teaching mode according to the method of the law of teaching innovation of piano students to enhance students' interest in learning, enhancing students' creativity, and let students experience the charm of art in the study with understanding the function of art and value to enhance student performance and the power from the connotation.

\section{Piano Teaching Innovation Model Should Follow the Basic Principles}

The principle of combining theory with practice. Music theory, piano theory are the basis for students to learn the piano, solid theoretical foundation is an important prerequisite for piano learning, some people attach importance to skills and despise the theory of learning. In fact, theoretical education and piano education must go hand in hand with the development. In practical teaching, some people can easily distinguish the wrong pitch which is caused by the lack of theoretical knowledge of students. [3] So the theory is not an abstract examination skills, but to promote students to understand the real music, and music theory and performance skills can enhance the catalyst.

Principles of cultivating College Students' initiative construction. Education is never one-sided, in the piano teaching innovation model, it is necessary to pay attention to the guidance of 
teachers making students improve their professional skills, but also to promote the students, improve innovation, active construction of knowledge, and to participate in the innovation of teaching, so as to achieve optimal learning effect. [4]Students are not passive recipients, which means the teacher is not only the active donor, education workers have their consciousness to promote the students' progress.

Pay attention to the cross discipline. The new piano teaching mode should not only attach importance to the development of the piano, but to pay attention to the interdisciplinary. In the construction of piano teaching mode, it can influence other reference system on piano teaching in music, dance, education and psychology into one, and more channels to expand the teaching method needs look for inspiration for Piano Teaching from the broader field.

\section{The Ways of Construction of Piano Teaching Innovation mode}

Enhancing the consciousness of reform. In the construction of the innovation mode of piano teaching, the reform is the most important aspect. This puts forward higher requirements for educators. Educators must have the consciousness of reform, because in the past teaching, teachers guide the teaching activities, and the students' independent learning consciousness and innovation consciousness are poor which means students' ability is not fully play. The students do not meet the requirements of the development of the times. Teachers should be used to reform, break the tradition to the rational use of the past teaching habits, and innovate teaching methods to promote the education of the educated as the dominant. In addition, teachers should reform in many fields to improve the teaching level and students' piano skills and artistic accomplishment.

Pay attention to the construction of team of teachers. On the piano teaching innovation model construction and personnel training, the teacher is undoubtedly an important part. Under the new situation, the training of qualified teachers with high quality, strong business, to understand the history of music and music theory, education, love music, love piano, love the students is particularly important. So educators should uphold the concept of lifelong learning, update their knowledge, broaden their knowledge, practice playing skills, pay attention to the combination of theory and practice, learn psychology and education, and the ability of students' psychology and habits to actively learn advanced experience at home and abroad with improving the professional quality. Good teachers should not only focus on business, but also have a high sense of responsibility and morality, so in teaching and innovation, teachers should treat the work and students with a sense of ownership without conservative in order to ensure the evergreen tree of the arts.[5]

The Department in charge of education according to the characteristics of teachers, strengthen the internal and external training for piano teachers, so as to urge teachers from the external point of progress, but also to protect the system for teachers' lifelong learning system.

Classroom teaching innovation. e performance of music is largely random and inspirational. It is the result of human evolution and the four-dimensional form of higher animals. This kind of inspiration comes from the accumulation of music in daily life, it is very difficult to achieve this without certain musical accomplishment. In the piano teaching, teachers should fully understand the characteristics. To strengthen the knowledge of music and auditory accumulation in the process of the class will be full time to the students, encouraging students of improvisation, in this way the students' innovation ability can be exercised. In the teaching practice, teachers can innovate the teaching methods, such as in the classroom, teachers cultivate students' innovation ability, but do not give students score, while by playing some music teachers play or passages to encourage students to carry out sorting and processing of this paragraph, and the final output into their own understanding of the passage played out. The teacher can also carry on the crosswise training, lets the student play a tune in a variety of ways and trains the student to innovate and the divergent thinking ability. Teachers can also use the psychological characteristics of young people not to be outdone, organizing the students some games which can have a variety of contents, for example according to a theme song and so on improvisation, with creative thinking of the students into the appraisal basis, promote the students' creativity from the outside. 
Teaching platform innovation. the platform, because of unique professional piano concert, with its highly contagious and flexible performance form widely popular, the concert can be used as teaching platform for students to display their talent, performance, testing learning outcomes of students, stimulate students' interest in learning. The teachers can held a small concert in the internal students, carefully organize programs, programs, and allow students to participate in the planning and performance, this means through the observation of the concert, the increasing effect of peer education, and achievement is relatively backward students by performing the excellent students to watch to enhance the concept of competition from the source to stimulate students interest in learning.

In addition, teachers and schools can also use modern network technology to play a role in the education of students. For example, the excellent student's work and the concert video uploaded to the campus network, through the whole school students to watch, stimulating students' creative desire and creative inspiration.[6] Also through the video site evaluation function, so that students quickly understand the feedback of teachers and students, prompting students to think about the performance of the play in order to better the next step of learning. Through the positive feedback of students, it can greatly stimulate the students' sense of pride, so that the students' emotional learning is full of confidence.

In addition, there are updated social platform can be used for education, such as WeChat group, QQ group, live platform and so on. Because these software has the function of video broadcast. In particular, the most convenient platform for a variety of live. Compared with the traditional piano teaching method, virtual broadcast platform more interesting, but puts forward new requirements for teachers' curriculum design ability and the ability of using the network, teachers in the professional field, photography and behavioral aspects to strengthen their knowledge reserves. In the network era, teachers should enhance their awareness of innovation and cultivate their creative thinking ability. [7]At present, some colleges and universities in the developed areas have made good use of the network broadcast platform, which greatly breaks through the limitation of traditional teaching time and space so as to achieve the effect of interesting teaching. Teachers combine the design of teaching and the performance of students with the use of network broadcast platform, real-time signal is transferred. The school can organize the students and teachers in the department to watch and comment. Other students or social music lovers can also observe. With the advent of the Internet era, there will be updated technology that can be used. It is important for the educators to innovate their minds and be good at discovering all kinds of innovative teaching models to provide a variety of ideas for piano teaching reform.

For piano teaching, campus culture is a big platform, the piano education is integrated into the campus culture to establish a broad class, namely the enhancement of students' interest in learning, but also enrich the cultural life of the campus. For example, the piano accompaniment can play a huge role in the school's Music Festival, art festival, sports meeting and other ceremonies. Piano fusion lives in the campus culture means the performance of the piano makes all kinds of ceremonies become more artistic appeal. Through this kind of infection, it can react with the students, stimulate the enthusiasm of the students and the enthusiasm of the creation, thus more in line with the teacher in practice to enhance the interest in piano learning. [8]

\section{Conclusion}

As we all know, twenty-first Century is the era of talent, and talent training is the continuing concern of all educational systems. Compared with other disciplines, the piano education is full of artistic education, which means piano education as the basis for the development of high-quality piano player, and the value of the subject has been fully affirmed. Nevertheless, the development of piano education must keep pace with the times. The innovation of the subject is inseparable from the efforts of piano educators, educational authorities and research institutions. Learning from the advanced experience of a variety of channels to build innovative piano education, enrich and improve the existing piano education system, so that the education and teaching can be better for the development of intelligent and innovative talents. 


\section{References}

[1] iaona Wu.Construction and reflection on the innovation mode of Piano Teaching[J].Journal of Wuhan Conservatory of Music.2009(1).

[2] ihong Zhan, Xiaona Wu.Investigation and analysis of piano teaching mode to promote the development of students' innovative quality[J].Art Research.2010(2).

[3] uzhi Hu.The application of hierarchical teaching mode in Piano Teaching in Higher Vocational Colleges[J].Art Education.2011(1).

[4] uixia Li.Study on the collective teaching of digital piano[J].Journal of Hebei University of Engineering(Social Science Edition).2008(4)

[5] ei Min. The application of convergent thinking in Piano Teaching -- a brief talk on the innovation of piano teaching $[\mathrm{J}]$. Musical space and time. 2014 (16)

[6] $u$ Lei. The practice of piano teaching reform in Universities under the concept of [6] quality education [J]. Northern music. 2017 (06)

[7] ang Lanchun. applied undergraduate college elective course teaching present situation about [J]. Northern music. 2017 (06)

[8] ang Yan.on the nationalization of piano education in Colleges and universities in ethnic minority areas [J]. Music time and space. 2015 (23) 